\title{
Advancement in materials for energy-saving lighting devices
}

\author{
Tak H. KIM, Wentai WANG, Qin LI (ه)
}

(C) Higher Education Press and Springer-Verlag Berlin Heidelberg 2012

Abstract This review provides a comprehensive account of energy efficient lighting devices, their working principles and the advancement of these materials as an underpinning to the development of technology. Particular attention has been given to solid state lighting devices and their applications since they have attracted the most interest and are the most promising. Solid state lighting devices including white light emitting diodes (LEDs), organic LEDs (OLEDs), quantum-dot LEDs (QLEDs) and carbon-dot LEDs (CLEDs) are promising energy efficient lighting sources for displays and general lighting. However there is no universal solution that will give better performance and efficiency for all types of applications. LEDs are replacing traditional lamps for both general lighting and display applications, whereas OLEDs are finding their own special applications in various areas. QLEDs and CLEDs have advantages such as high quantum yields, narrow emission spectra, tunable emission spectra and good stability over OLEDs, so applications for these devices are being extended to new types of lighting sources. There is a great deal of research on these materials and their processing technologies and the commercial viability of these technologies appears strong.

Keywords energy-saving lighting devices, solid state lighting devices

\section{Introduction}

One fifth of global power consumption is used for lighting [1], therefore, it is very important to develop energy-saving lighting devices as part of an energy sustainability strategy. New generations of lighting devices are continually being developed owing to discoveries and advancements in new materials and lighting technologies. Lighting devices have been utilized in various forms and for various applications

Received August 20, 2011; accepted November 18, 2011

E-mail: Q.Li@curtin.edu.au and can be categorized into general lighting and specialized lighting. General lighting refers to both indoor and outdoor lighting which is the most common form of lighting. Specialized lighting refers to lighting with more specific areas and functionalities. Figure 1 shows lighting devices categorized by their applications.

Fluorescent lamps have been used in offices and homes as a low-cost, energy-saving light source for more than 60 years and are a good alternative to incandescent lamps. Fluorescent lamps represent a significant advancement in technology since they consume $2-5$ times less power and last 8-10 times longer than incandescent lamps. However, lighting technologies have continued to develop in order to bring more efficient lighting as well as to minimize environmental hazard issues [2].

Lighting devices emit photons of different wavelength ranges, depending on the luminescent material used and the mechanism for light generation. White light emitting devices are currently in high demand because of the fast growing electronic display industry. Unlike old-type cathode ray tubes, liquid crystals do not emit light themselves, so they need a light source called a backlight unit in order to function as display devices $[3,4]$. Due to the enormously increasing demand for large and small displays, there are huge needs for better quality backlight units. Large display devices such as TVs are becoming bigger and hence they need brighter and more efficient backlighting devices; whereas small display devices such as mobile phones and notebook computers require more energy efficient backlights for better battery life.

White light emitting devices such as fluorescent lamps were initially developed for general lighting as well as for industrial lighting [5-7]. Although it has been more than 100 years since fluorescent lamps (FL) were initially utilized for lighting applications, the growth of information technology and the related display technologies has brought new demands for quality white lights and better lighting devices. At the time when thin film transistor (TFT) LCD display devices first became commercially available in the late 1980 s, there were not many choices for backlights and compared to incandescent lamps, FLs were 

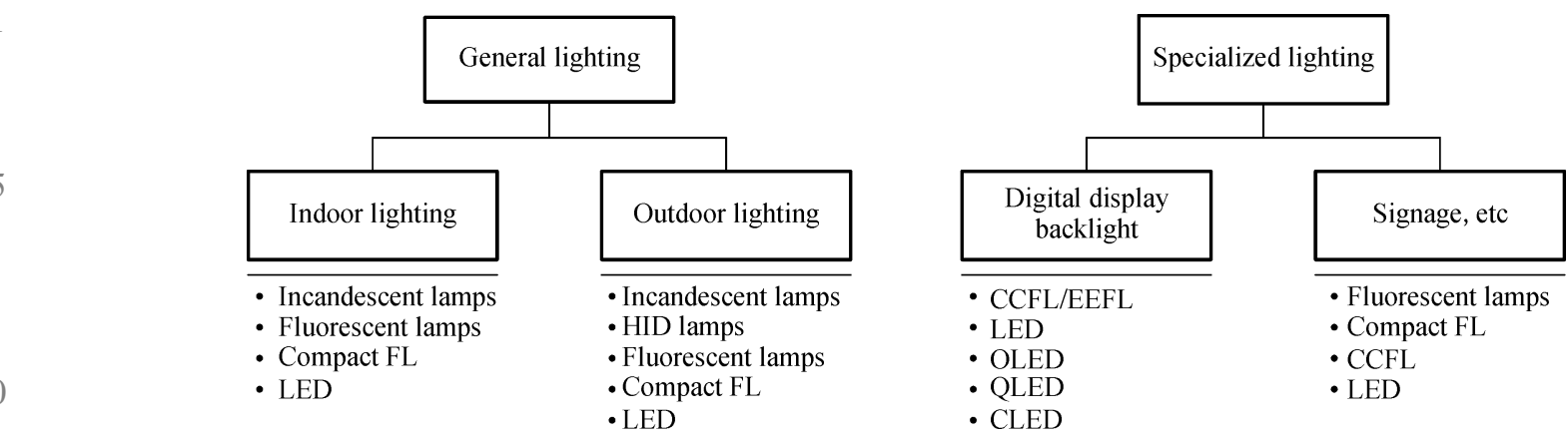

Fig. 1 Types of lighting applications and types of lamps used (FL: fluorescent lamp; HID: high intensity discharge; CCFL: cold cathode fluorescent lamp; EEFL: external electrode fluorescent lamp; LED: light emitting diode; OLED: organic light emitting diode; QLED: quantum-dot light emitting diode; CLED: carbon-dot light emitting diode)

the better choice due to their better energy efficiencies and more suitable emission spectra $[3,7]$.

Because of the fast development of material technologies and their related processing technologies, conventional types of FLs are disappearing fast and being replaced by solid state lamps as backlighting devices [8]. These solid state lamps are promoted as being higher efficiency and better quality than FLs. However, so far their applications are very limited in display areas because of their higher costs and because of current technical barriers such as size limitations and fast blue color degradation $[9,10]$.

In this review, a comprehensive account of energy efficient lighting devices, their working principles and the advancement of these materials as a key driver in the development of technology is provided. Particular attention is placed on solid state lighting devices and their applications since they have attracted the most interest and are the most promising. Figure 2 presents the typical varieties of solid state lamps and their applications. All these newly developed lighting devices are considered to be promising technologies.

\section{Fluorescent lamps}

It has been more than 100 years since the first mercury vapor lamp was patented by Hewitt [11] His lamps have better efficiencies and lifetimes than carbon-filament incandescent bulbs. The development of efficient longlasting electrodes and suitable fluorescent phosphor materials to convert the invisible ultraviolet light into visible light made these lamps a commercial reality in the 1940s. Since then fluorescent lighting has been used in offices and homes as a low-cost, energy-saving light source. In addition FLs have been further developed as a light source for LCD display devices.

Most FLs use mercury vapor along with a small amount of an inert gas mixture [12-17]. The inner surface of the tube is coated with a phosphor. The other key element is the electrodes. When the fluorescent lamp is on, a large number of free electrons are generated from the electrodes. The electrons migrate through the gas from one end of the tube to the other. As the electrons and charged atoms move through the tube, some of them collide with the gaseous mercury atoms. These collisions excite the electrons in the mercury atoms into higher energy levels. When the electrons return to their original energy level, they emit UV photons. The UV light is then absorbed by the phosphor and reemitted as visible light.

The amount of light emitted from the tube depends on the phosphor used. The wavelengths radiated by the phosphor vary with the chemicals used to make the phosphor. For instance, the phosphor used in FLs are generally halo-phosphates which contain calcium, antimony, chlorine, fluorine and manganese [18].

FLs are generally categorized by the electrode type, as

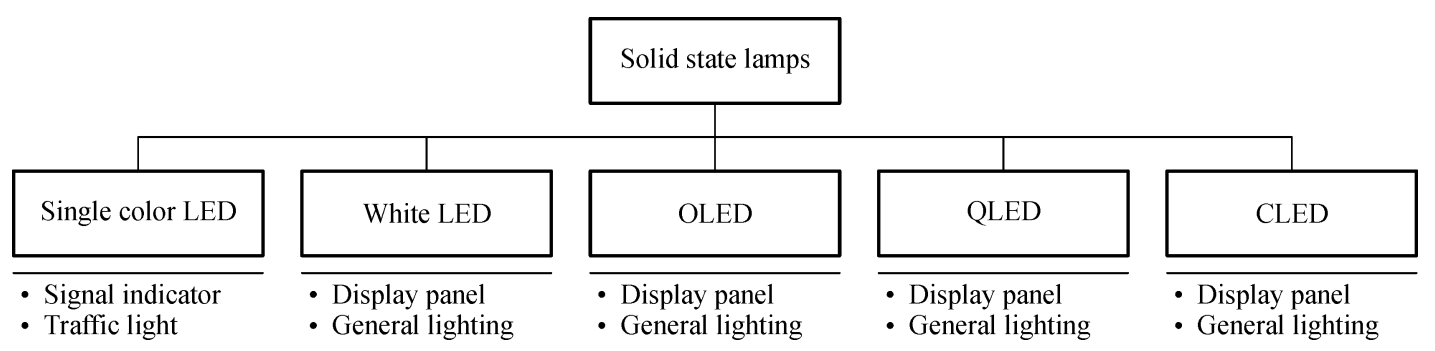


illustrated in Fig. 3. There are many electrode types with different shapes and materials but for FLs there are mainly two types of operational modes. FLs that use coiled tungsten can be categorized as hot cathode lamps; these operate at high temperatures to liberate electrons and are the most common type. The other type is a cold cathode FL (CCFL) which operates at high voltage to liberate electrons. As shown in Fig. 4, unlike conventional FLs or compact fluorescent lamps (CFLs), the cathodes used in CCFLs are metals that are constructed to maximize surface area. Nickel is generally selected as the cathode material because it results in easier manufacturing, better electrical properties and lower material cost $[4,19,20]$.

In addition to the different operational mode, CCFLs have the advantages of smaller size, longer lifetime and higher efficiency [21]. Therefore they have been used as light sources for LCD panels. There are other types of cold cathode lamps including external electrode fluorescent lamps (EEFL) and flat fluorescent lamps (FFL). EEFLs have other benefits over conventional CCFLs, the most attractive of which is the absence of electrodes in the discharge tube, which is the major factor that limits the lifetime of the lamp [22-26]. A FFL is a flat shaped CCFL. The operational theory is the same as for the CCFL and the electrodes can be both internal and external. It has better light uniformity when it is applied as the light source for LCD panels $[3,27-29]$.

Although cold cathode lamps offer better performance than conventional FLs and CFLs, they require a discharge tube and a tube that contains at least a milligram of mercury. Mercury-free discharge lamps which utilize a phosphor and plasma technology have been designed to replace mercury filled systems. A xenon gas mixture is a well-known alternative plasma source, however it is not as efficient as mercury and is much more expensive [27,30].

Despite the many advantages that CCFLs have over conventional FLs, the operation principles and required materials remain the same as FLs. In one of the most efficient FLs, only $63 \%$ of energy can be converted to UV radiation. After the UV radiation is converted to visible light by the phosphor, the overall efficiency of the fluorescent lamp cannot exceed 28\% [31]. All fluorescent lamps emit UV light and contaminate the environment with mercury and phosphor when broken or disposed of after use. Because of their shapes and the structure of the materials, collection and recycling of the lamps is not applicable to every situation. Therefore CCFL for LCD backlights are fast disappearing due to the development of more efficient, more environmentally friendly and brighter LEDs.

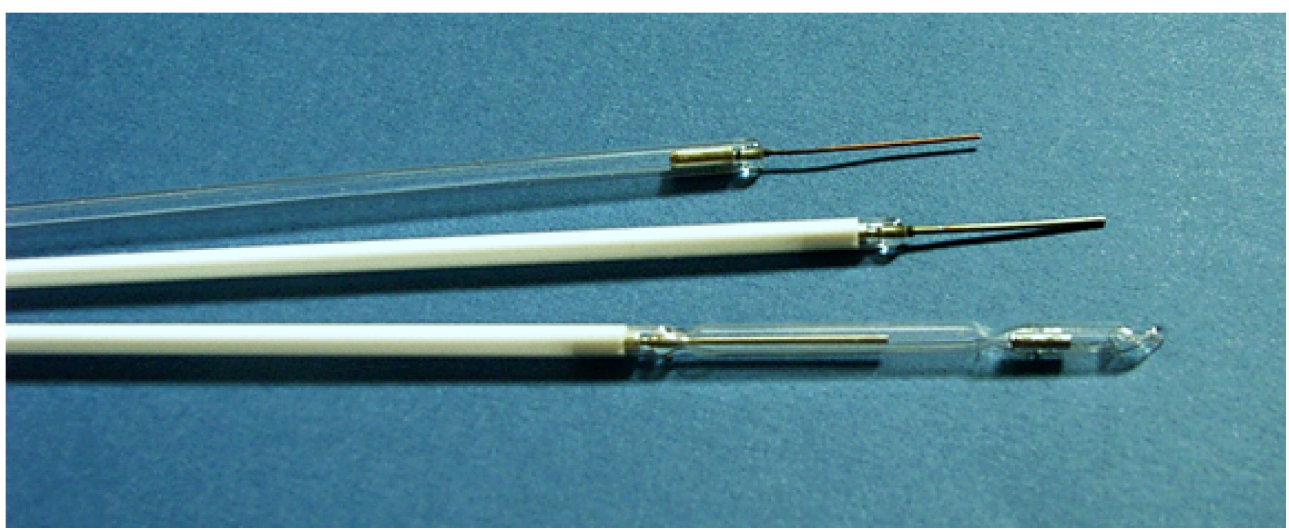

Fig. 4 CCFLs for LCD monitor applications 


\section{Solid state lighting devices}

\subsection{Light emitting diodes (LEDs)}

5 Electroluminescence was first discovered by Round in a crystal of silicon carbide and nearly 60 years later the first practical p-n junction emitter of red light was developed by Holonyak and Bevacqua [32]. The development of light emitters from gallium nitride and related materials by

10 Nakamura et al. in 1994 resulted in a new generation of white light emitters [33,34].

A light emitting diode (LED) is a solid state semiconductor device which is closer to a semiconductor chip than a lighting device. As shown in Fig. 5, it is a

15 semiconductor device with a junction formed by joining $\mathrm{p}$ type and n-type semiconductors together. Like a regular diode, electrical current flows across the junction in only one direction. When current is flowing, the LED is forward-biased, and the LED emits light.

20 Typically GaAlAs (red), AlGaInP (orange-yellowgreen), and $\mathrm{AlGaInN}$ (green-blue), which all emit monochromatic light at a frequency corresponding to the band gap of their semiconductor compounds, are used. These conventional LEDs do not emit polychromatic light, i.e. white light. White LEDs can be used as light sources and are capable of producing full color displays with existing color filtering technology. One method used to produce white light is to combine individual LEDs to simultaneously emit the three primary colors, which mix to 30 produce white light. Another method is to use a yellow phosphor to convert monochromatic blue light to white light, or to use two or more phosphors emitting different colors to convert UV light, although color control is limited by this approach. Figure 6 shows the basic structure

35 of a phosphor based white LED. Phosphor based white LEDs are less efficient than monochromatic versions since they rely on a phosphor coating to convert the monochromatic emission, which is usually blue, to white light. Much efficiency is lost during the phosphor conversion process.
Red, yellow and green LEDs have been used in various applications including electronic information panels which display characters on panels. However green and blue LEDs do not emit light as strongly as red LEDs. Until the development of gallium nitride LEDs, full-color LED displays were impossible due to the inefficiency of the green and blue LEDs [33,34].

The development of GaN-based blue LEDs has been a key for the development of current LED technologies. The efficiencies of different LEDs are shown in Table 1. The use of GaN-based LEDs not only significantly improves the efficiency, but also enables the production of monochromatic multichip-based full-color LEDs as well as phosphor-based white LEDs.

Although white LEDs require a much higher initial cost than conventional FLs, modern LEDs are much more energy-efficient than FLs. Moreover, the lifetime of LEDs normally exceeds $50000 \mathrm{~h}$ which is twice that of fluorescent lamps. There are also other benefits over FLs including shock resistance and ease of fabrication or microfabrication since LEDs are solid state devices. For example, it is very easy to design a single LED structure that is as small as the tip of a matchstick. LEDs have been the focus of intense research and development because they are brighter, more flexible to design, more efficient and last longer than FLs. The application areas for LEDs are broad ranging from advertising signs to water disinfection and thus they have an enormous market potential.

With the modern world's insatiable appetite for large and small display devices, LEDs are increasingly used in modern display technologies. The use of LEDs as backlighting devices in digital display devices has brought faster responses, broader color spectrums, longer lifetimes, thinner structures and no mercury [36,37]. However, compared to traditional light sources such as CCFLs, LEDs remain relatively expensive and require precise current control and heat management. Most of all, there is a minimum required thickness for LED backlight-based

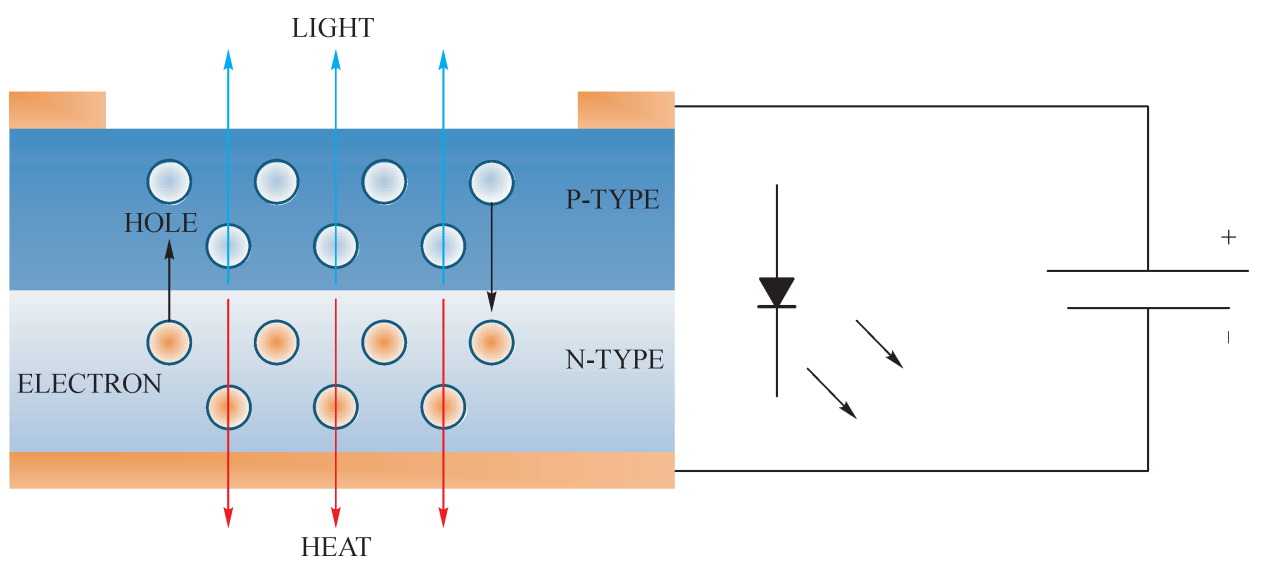

Fig. 5 Basic working principle of an LED 


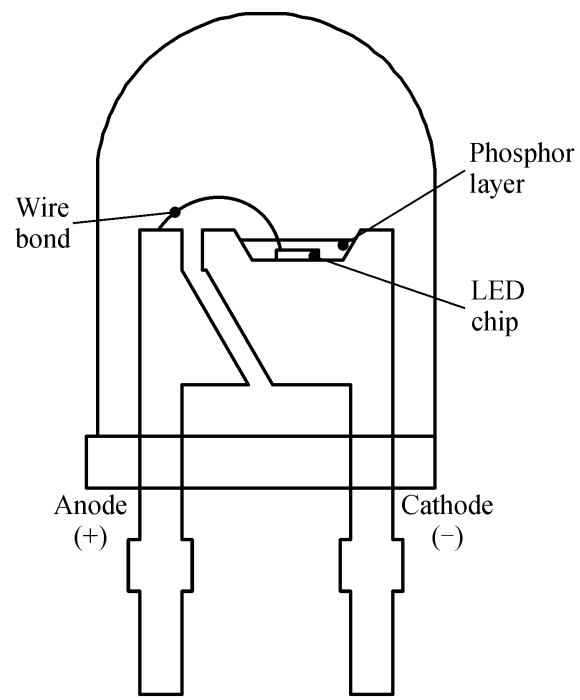

(a)

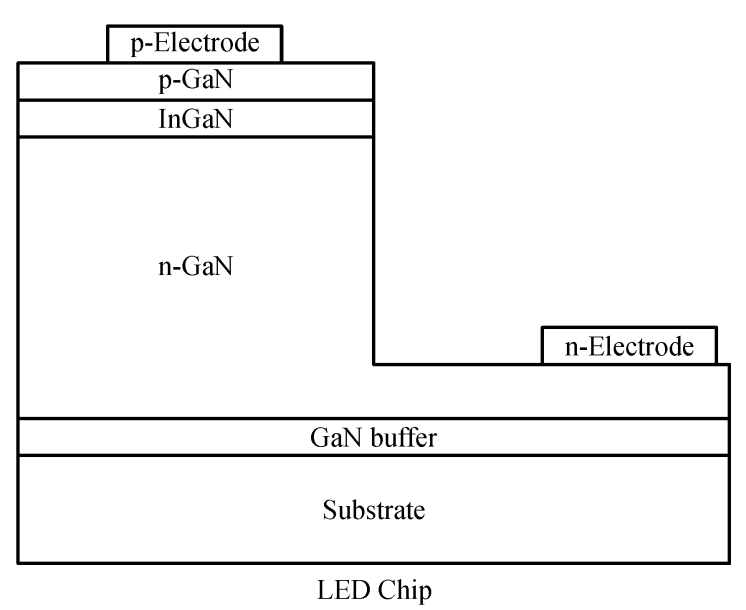

(b)

Fig. 6 (a) Structure of a phosphor based white LED (b) LED chip structure in a phosphor based white LED [34]

Table 1 Comparison of red, green and blue LEDs [33,35]

\begin{tabular}{lllll}
\hline LED color & Material used & Luminous intensity $/ \mathrm{mCd}$ & Output power $/ \mu \mathrm{W}$ & External quantum efficiency $^{\mathrm{a})} / \%$ \\
\hline Red & GaAlAs & 1790 & 4855 & 12.83 \\
\multirow{2}{*}{ Green } & GaP & 63 & 30 & 0.07 \\
& $\mathrm{InGaN}$ & 2000 & 1000 & 2.01 \\
& $\mathrm{SiC}$ & 9 & 11 & 0.02 \\
Blue & $\mathrm{InGaN}$ & 1000 & 1200 & 2.16 \\
& $\mathrm{InGaN}$ & 2500 & 3000 & 5.45 \\
\hline
\end{tabular}

a) Ratio of the total number of photons emitted outside the device in all directions to the number of electrons injected

displays since a certain distance between the LED light sources and the optical films is essential for achieving a uniform distribution of light [38]. Due to the technical thickness requirements of optical films, the use of thin-film LEDs is the current trends for thinner display devices.

\subsection{Organic light emitting diodes (OLEDs)}

It has been 60 years since electroluminescence in organic materials was first reported by Bernanose [39]. But the field of organic displays and lighting technology only took off after the work by Tang and Vanslyke in 1987 [40]. It has since been expanded to a wide range of applications. Since the light emission from conjugated polymer-based LEDs was first reported by Burroughes et al. in 1990 [41], there have been incredible developments leading to practical applications. Active matrix polymer LED display devices are now a commercial reality ${ }^{1), 2}$.

Organic LEDs are light emitting devices that use a phenomenon whereby light is generated by combining an electron and a hole in an organic light emitting layer. When a forward bias voltage is applied between the anode and the cathode, electrons and holes are injected into the organic light emitting layer through the metal cathode or through the indium tin oxide anode boundary. Essentially, the electron-hole carriers combine in the emitting layer to generate photons and attain light emission.

As shown in Fig. 7, an OLED is generally comprised of an anode, a cathode and an organic electroluminescent unit sandwiched between the anode and the cathode. At a minimum, the organic electroluminescent unit includes a hole transporting layer, a light emitting layer and an 45 electron transporting layer.

OLEDs have great potential due to their applications in display devices and lighting devices. Most of the technological progress on OLEDs has been driven by display applications for manufacturing clearer and brighter display panels which are already commercially available for portable electronic devices as well as flexible display panels. Although inorganic material based LEDs work 


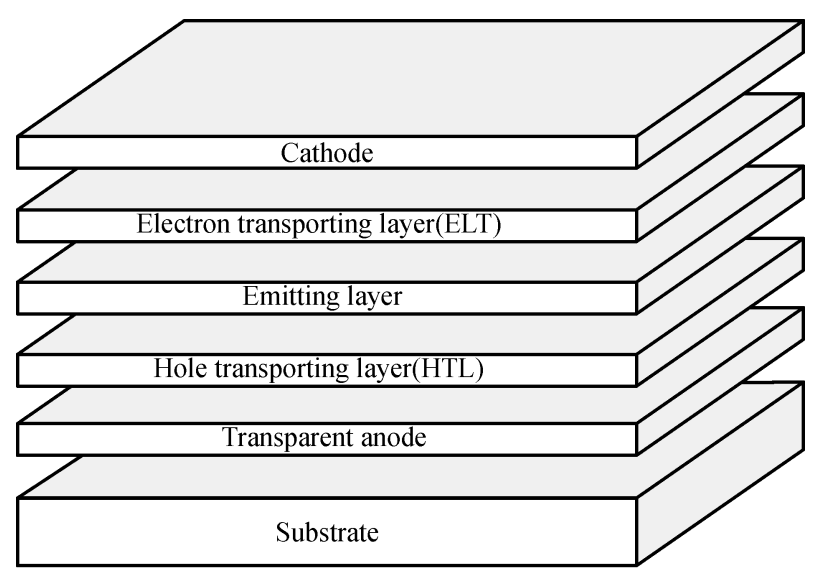

15
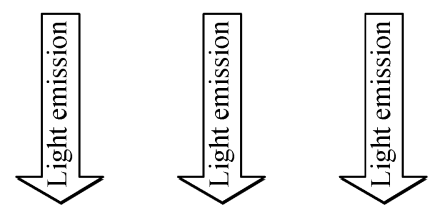

Fig. 7 A typical structure for an OLED

well for many applications including display panels, they require larger spaces and have less physical flexibilities

25 than OLEDs. OLEDs also have numerous advantages over the larger LEDs: OLEDs are made with semiconducting polymers so they can be easily manufactured through various printing technologies; they can be printed on large areas onto any type of materials such as glass or plastic substrates and they are lower cost and lighter weight.

There are a number of ways to process each layer. Any suitable process such as evaporation, sputtering, chemical or physical vapor deposition, electrochemical deposition or printing can deposit the desired materials on each layer.

35 For example, the substrate can be a piece of flat glass and the anode can be a transparent material with a high work function for hole injection. The transparent anode which is normally indium-tin-oxide (ITO) can be deposited on the glass substrate by a sputtering process. The hole

40 transporting layer (HTL) which is p-type semiconductor polymer can be coated on top of the anode by spin coating which is then further treated by UV light to cure. The emitting layer can be deposited by inkjet printing which is then heat treated in order to cap the organic ligand.

45 The electron transporting layer (ETL) which is a metal oxide or n-type semiconductor polymer can be deposited by vapor deposition. The cathode must have a low work function for electron injection. The metal such as aluminum or a $\mathrm{LiF} / \mathrm{Al}$ alloy can be deposited by thermal 50 deposition [10,42-51].

The emitting layer generally consists of light emitting polymers or dopants in a suitable host material. Dopants in a suitable host material can be produced by doping a charge-transporting compound, i.e. doping the host material with a fluorescent compound or a phosphorescence-emitting compound. Table 2 shows the materials used for each layer and Fig. 8 shows the absorption and emission spectra of typical semiconducting polymers.

OLEDs can emit different colors depending on the properties of the light emitting layer. A number of approaches have been investigated to produce white light emission which is crucial for both display panel backlights and general lighting. One approach is to dope a single emissive layer with micro-patterned color filters. Another is to pattern RGB emitters using a selective deposition method. The last is to stack different color emitters where all emissions from each layer are combined to give off white light [54-62].

OLEDs can also be fabricated relatively inexpensively to provide a variety of colors and white light. However OLEDs generally suffer from deficiencies in efficiency and in lifetime relative to inorganic devices. This is because the light-emitting layer, being an organic material, typically requires a relatively high current density and driving voltage to achieve high luminescence which exacerbates the degradation of the OLEDs, especially in the presence of oxygen, water and UV photons [43].

Even though numerous OLED products are commercially available, there are still issues to solve such as complications in the manufacturing process, processing time, size limitations, lifetime of the organic materials, stabilization problems with humidity and faster degradation of some color emitters. Nevertheless, OLEDs are promising because of the potential lower manufacturing cost in the long term [59].

\subsection{Quantum-dot light emitting diodes (QLEDs)}

Semiconductor quantum dots have attracted significant attention due to their interesting optical properties such as narrow emission bands, emission tunability, high quantum yield, and optical stability. These properties make QDs attractive materials for LED applications. Synthesis of monodispersed cadmium selenide semiconductor nanocrystals by using tri-n-octylphosphine oxide was first performed by Murray et al. [63]. An early prototype of QLEDs was made with CdSe nanocrystals using the above synthesis method and a semiconducting polymer were demonstrated by Colvin and coworkers in 1994 [64]. Since then QDs, whose bandgap can be controlled by adjusting their size, have been pursued for producing white light or other defined emission spectra by combining them with organic semiconducting materials and OLED structures [64-67].

Similar to OLEDs, QLEDs are light emitting devices that use a phenomenon whereby light is generated by combining an electron and a hole in a single QD light emitting layer or in multiple QD light emitting layers. When a voltage is applied, electrons and holes are injected into the light emitting layers through the cathode and the anode boundaries. Essentially, the electron-hole carriers combine in the emitting layer to generate photons. 
Table 2 Materials for OLED layers [10,42-52]

Layer
Emitting layer

Electron transporting layer
Materials

- Indium tin oxide

- Indium zinc oxide

- Aluminum zinc oxide

- Cadmium tin oxide

- Tin oxide

- Zinc oxide

- 4,4'-bis[ $N$-(1-naphthyl)- $N$-phenylamino]biphenyl (NPB)

- 4,4'-bis[ $N$-(3-methylphenyl)- $N$-phenylamino]biphenyl (TPD)

- 4,4'-bis[N-(1-naphthyl)- $N$-(2-naphthyl)amino]biphenyl (TNB)

- 4'-carbozol-9-yl-biphenyl-4-yl-naphthalen-1-yl-phenyl-amine (NCB)

- Bis(4-dimethylamino-2-methylphenyl)-phenylmethane (MPMP)

- 3,3'-dimethyl- $N, N, N^{\prime}, N^{\prime}$-tetra-m-tolyl-biphenyl-4,4'-diamine (HMTPD)

- 4,4',4"-tris[(3-methylphenyl)phenylamino]triphenylamine (MTDATA)

- $N, N^{\prime}$-di-phenanthren-9-yl-4, $N^{\prime}$-diphenyl-biphenyl-4,4'-diamine (PPB)

- Tris(4-carbazol-9-yl-phenyl)amine (TCTA)

Dopants for host materials (complex of iridium, platinum, europium or ruthenium)

- Dichlorotris(1,10-phenanthroline)ruthenium(II) hydrate

- Lithium tetra(2-methyl-8-hydroxyquinolinato)boron

- Platinum octaethylporphyrin

- Tris(2,2'-bipyridyl)dichlororuthenium(II) hexahydrate

- Tris(2,2'-bipyridyl-d8)ruthenium(II) hexafluorophosphate

- Tris(benzoylacetonato) mono(phenanthroline)europium(III)

- Tris(1-phenyl-3-methyl-benzoimidazolin-2-ylidene- $C, C^{\prime}$ ) iridium(III)

- Iridium(III) bis[(4,6-difluorophenyl)-pyridinato- $N, C$ ]picolinate

Light emitting polymers

- Cyano-polyphenylene vinylene (CN-PPV)

- Poly(fluorenylene ehtynylene) (PFE)

- Poly(phenylene ethynylene) (PPE)

- Polyfluorene (PFO)

- Polyfluorene-vinylene (PFV)

- Polyphenylene vinylene (PPV)

- 1,3,5-tris(N-phenylbenzimidazol-2-yl)benzene (TPBi)

- 2-biphenyl-4-yl-5-(4-tert-butyl-phenyl)- [1,3,4]oxadiazole (PBD)

- Tris(8-hydroxyquinoline) aluminum (Alq3)

- 4,7-diphenyl- [1,10]phenanthroline (DPA)

- 4-naphthalen-1-yl-3,5-diphenyl-4- [1,2,4]triazole (TAZ-1)

- 3,4,5-triphenyl-4- [1,2,4]triazole (TAZ-2)

- Indium trisoxine [alias, tris(8-quinolinolato)indium]

- Lithium oxine [alias, (8-quinolinolato)lithium(I)]

- Zirconium oxine [alias, tetra(8-quinolinolato)zirconium(IV)]

- Magnesium-aluminum

- Magnesium-silver

- Magnesium-indium

- Aluminum-lithium

- Llithium fluoride

- Aluminum 


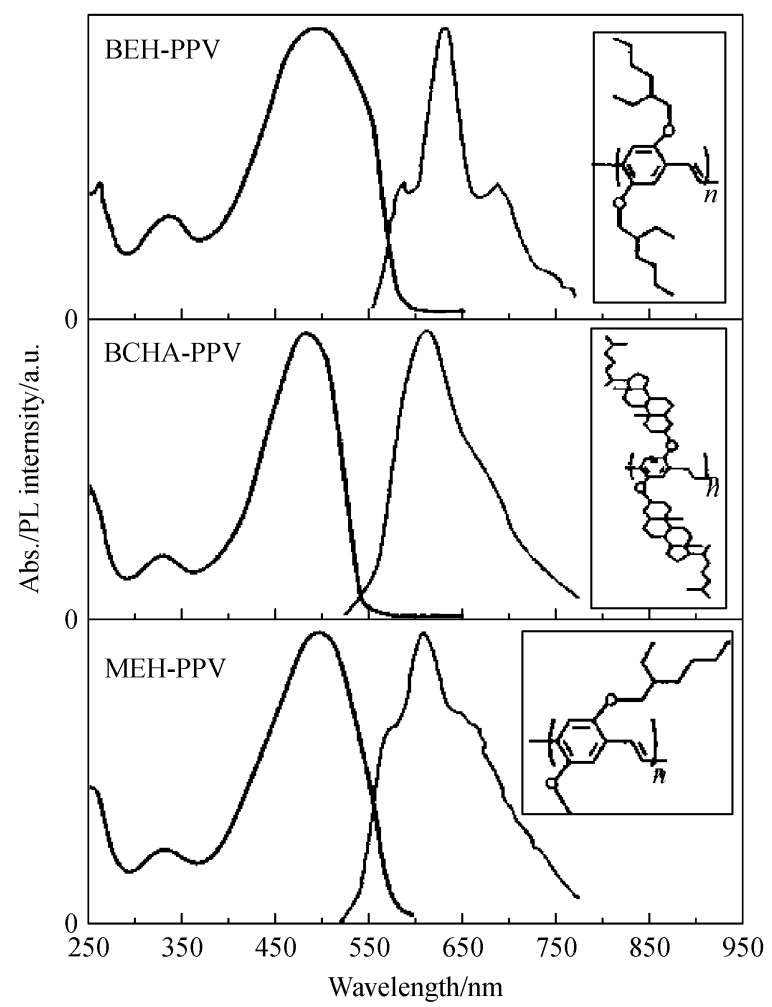

(a)

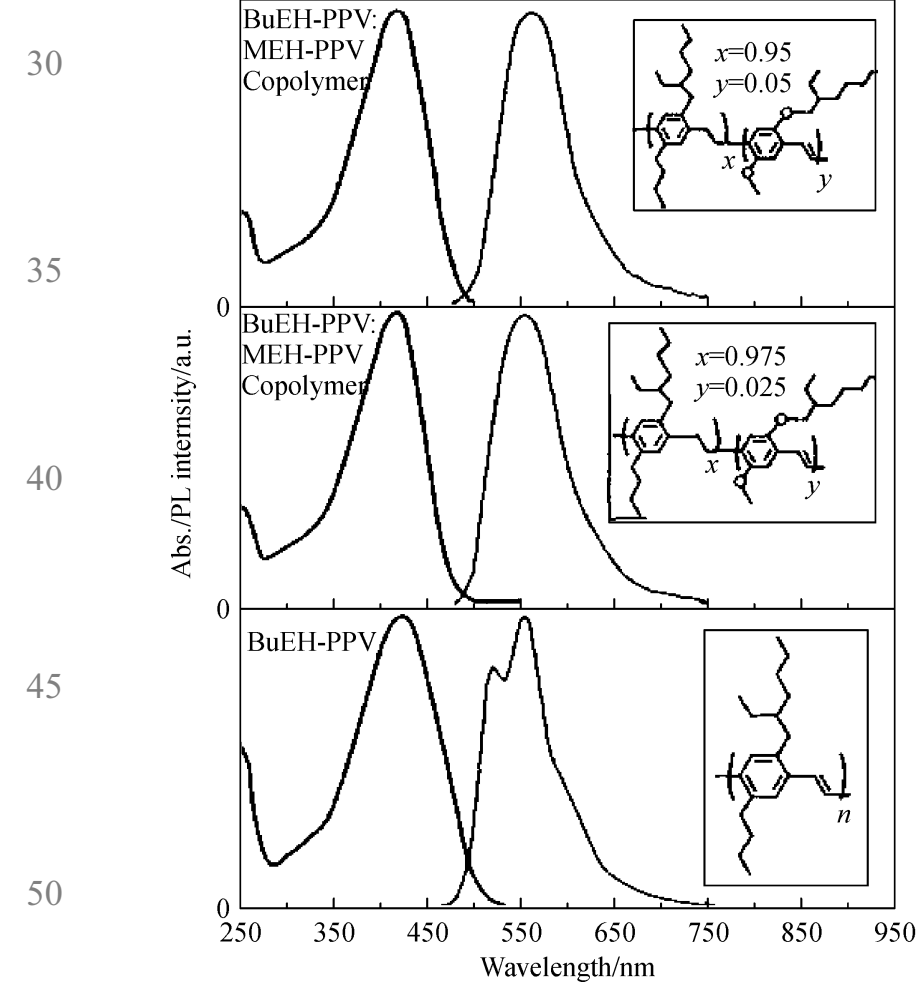

(c)

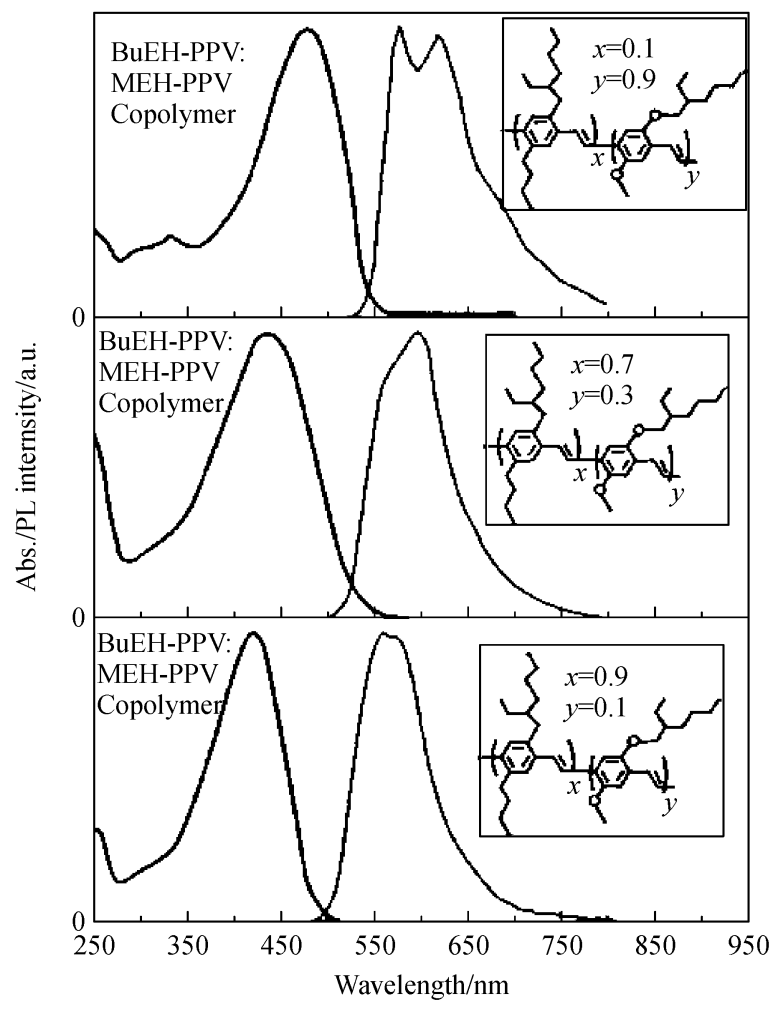

(b)

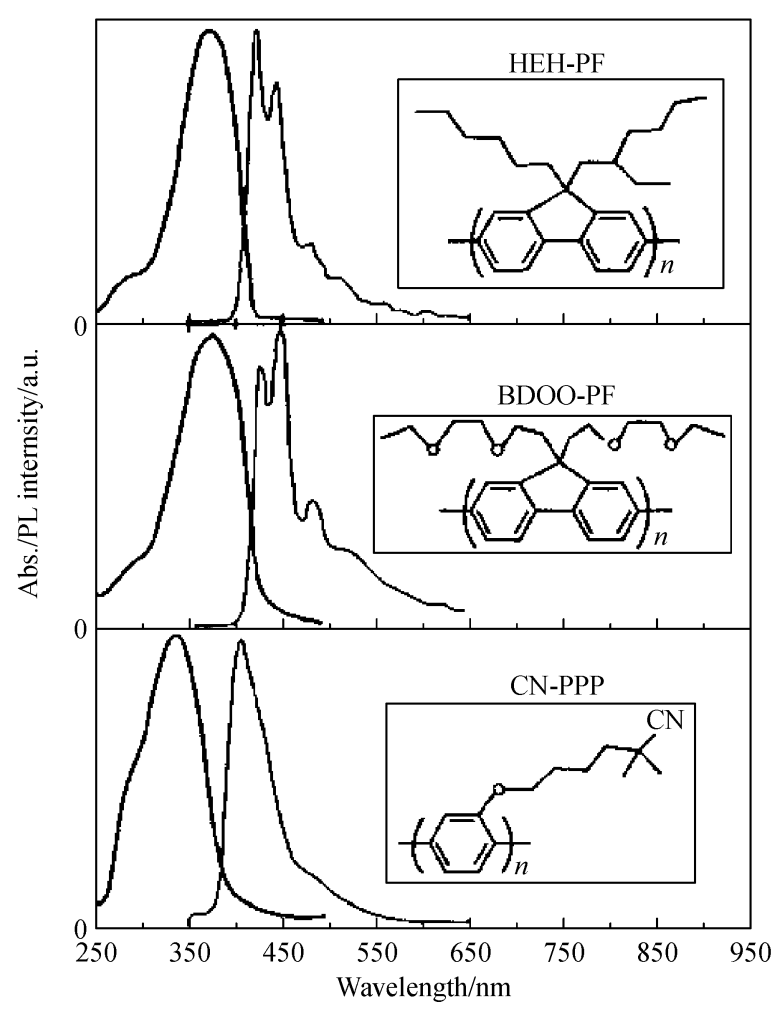

(d)

Fig. 8 Absorption (peak on the left) and emission (peak on the right) spectra of semiconducting polymers ([53]) 


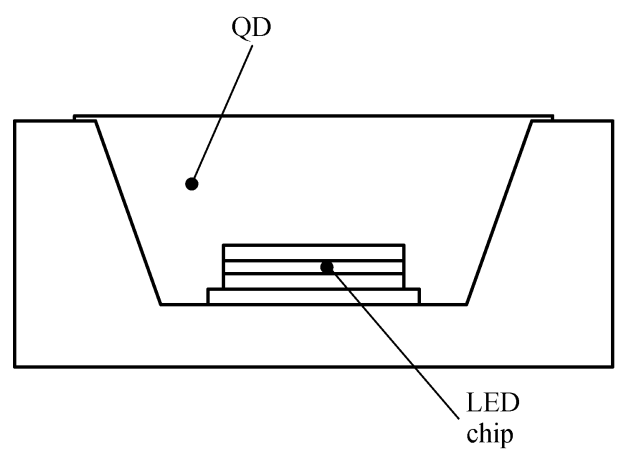

(a)

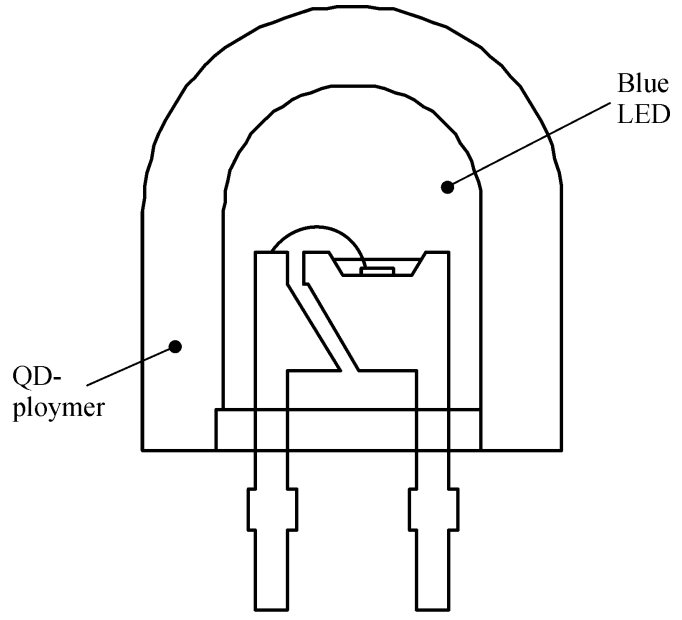

(b)

Fig. 9 QD applications as color changing media for LEDs (a) White LED for display backlight applications (b) White LED by using a blue LED $[68,69]$

Currently, there are three major approaches for display and lighting applications. As shown in Fig. 9, one approach is to use QDs as a color changing medium in a LED or on the surface of a LED. For example, the combination of a highly efficient blue light emitting GaN LED and a $\mathrm{CdSe}(\mathrm{ZnS})$ QD-polymer composite can be utilized for producing a full color emission spectrum $[68,69]$.

Another approach is to use monochromatic QDs incorporated with light emitting polymers in order to control the electroluminescent spectra. There are several reports regarding devices based on QD/polymer hybrids with stacked structures for improving the efficiency and quality [55,70-73]. Torriss et al. achieved white light emission by using poly ( $N$-vinylcarbazole) (PVK) and tris(8-hydroxyquinoline)aluminum (Alq3), with red-emitting QDs and blue-emitting organic molecules (iridium(III) bis(2-(4,6-difluorephenyl) pyridinato- $N, C 2) \operatorname{Ir}(\mathrm{III}) \mathrm{DP})$ [71].

The last approach is to use a core-shell type QD layer as the light emitting layer. As shown in Fig. 10, the basic structure is identical to OLEDs. Normally, a thin layer of luminescent QDs is inserted between a HTL and an ETL. When a forward bias (voltage) is applied, the holes and electrons are injected into the QD layer from the HTL and ETL, respectively. The recombination of the electron-hole pairs in the QDs generates photons and achieves the light emitting characteristics ${ }^{1), 2}$ [74,75]. Recently Kim et al. produced a full color display by patterning individual RGB QDs [75].

The performance of QLEDs depends on the QD assembly structure and the QD material. Commonly used materials for QDs as well as their performances are summarized in Table 3. QDs in LEDs should be a monolayer structure in order to overcome the poor conducting feature of QD multilayers [74]. Techniques that have been employed for making monolayers of QDs include inkjet printing, contact printing and transfer printing. Similar to OLEDs, there are also different structures for white light emission including RGB patterning or RGB stacked structures, as shown in Fig. 10.

The advantages of QLEDs over OLEDs and other LEDs include stability, solution processability, excellent color purity owing to the inorganic nature of the materials and narrow emission spectra for the QDs. Current QLEDs require layers of organic materials and reactive metals for efficient charge transport and injection. The use of the organic layers lessens the advantages of QLEDs and has weakened its competitive edge in commercial applications. Long-term stability is unsatisfactory due to degradation of the organic layers and oxidation of the reactive metals. For most QLEDs, defects can occur at the organic-inorganic interface between the QD-emitting layer and the organic electron transporting layer which leads to poor electron injection into the QD-emitting layer [74,77].

Some studies have been carried out to obtain fully inorganic QLEDs for better long-term stability [78-80]. However vacuum sputtering processes have to be applied for fabricating the ETL and the sputtering processes adds extra cost as vacuum sputtering is much more complicated and time consuming than fabricating organic ETLs.

1) Coe-Sullivan S, Steckel J S, Ritter J. Performance potential of quantum dot light emitting devices for display applications. AD'07: Proceedings of Asia Display 2007. Shanghai: East China Normal University, 2007, 1(2): 86-92 


\section{5}

10

15
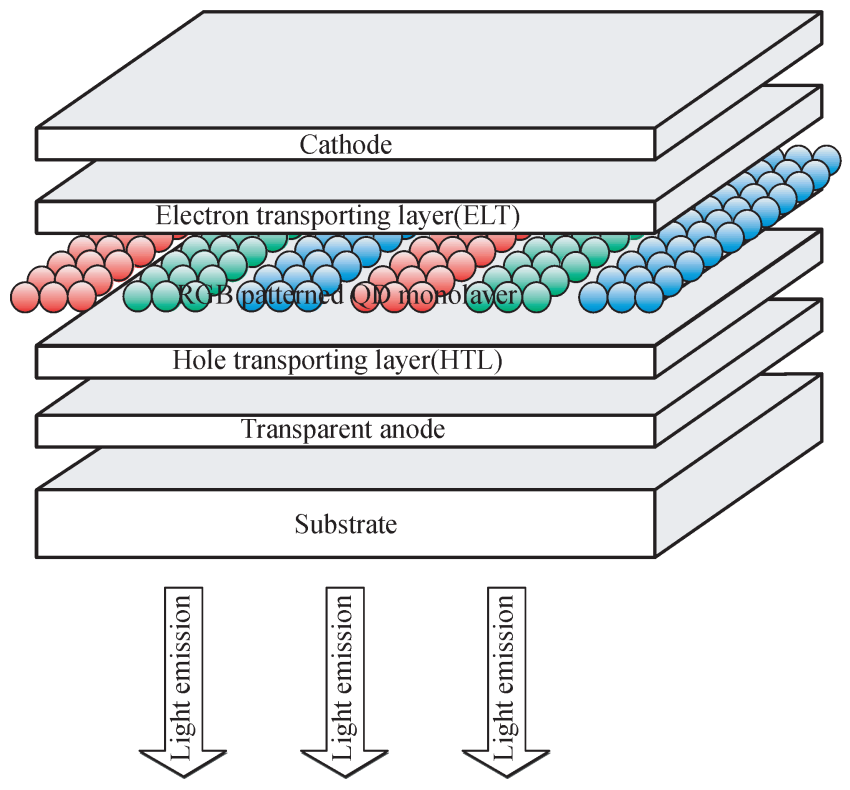

(a)
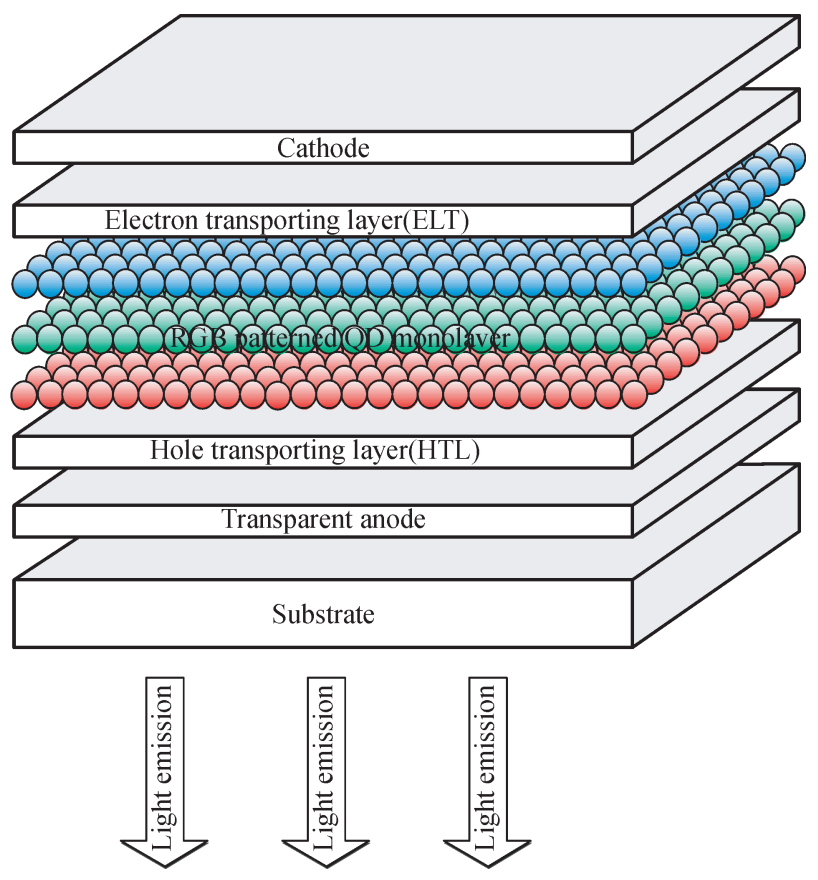

(b)

Fig. 10 QD applications of QLEDs and their structures (a) Patterned QD structures and QLED as a full color display device (b) Stacked QD structures and QLED as a white light emitting device [75]

Table 3 Electro luminescent (EL) colors and their QD materials [76]

30

\begin{tabular}{llll}
\hline EL color & Material (core/shell) & Luminance $\left(\mathrm{Cd} / \mathrm{m}^{2}\right)$ & External quantum efficiency $/ \%$ \\
\hline Red & $\mathrm{CdSe} / \mathrm{ZnS}$ & 7000 & 2 \\
Red & $\mathrm{CdSe} / \mathrm{CdS}$ & 100 & 0.8 \\
Red & $\mathrm{ZnCdSe}$ & 1950 & 0.1 \\
Green to red & $\mathrm{CdSe} / \mathrm{CdS}$ & 600 & 0.22 \\
Green & $\mathrm{ZnSe} / \mathrm{CdSe} / \mathrm{ZnS}$ & 28 & 2.6 \\
Orange & $\mathrm{CdSe} / \mathrm{ZnS}$ & 13 & 2.7 \\
Blue & $\mathrm{ZnCdS}$ & 15 & 0.4 \\
White & $\mathrm{CdSe} / \mathrm{ZnS}$ & 100 & 0.36 \\
\hline
\end{tabular}

Furthermore, the QDs contain heavy metals such as cadmium which have a high level of toxicity and limit their applications.

\subsection{Carbon-dot light emitting diode (CLED)}

Nano-sized luminescent carbon dots (CDs) were first introduced by Sun et al. [81]. Surface passivated CDs are considered to be a new class of nanomaterial that could 50 replace QDs due to their tunable emission spectra, chemical inertness and low toxicity [81,82]. Various studies especially in the area of biomedical imaging, have demonstrated that CDs have excellent optical performance and very low toxicity [82-84].
As an emerging material, research on CDs as light emitting devices is still in its infancy. A few studies have been performed and a proof-of-concept demonstrated that CDs could be applied to lighting devices [85]. Wang and coworkers demonstrated CD-based white light emitting devices by using an OLED structure and 1-hexadecylamine passivated CDs at $0.083 \%$ of the maximum quantum yield [86]. Figure 11 shows the structure of a CLED used for demonstrating the electroluminescence of surface passivated CDs. According to the production methods described, this device is comparable to devices using thin layers of QDs.

Since the research performed by Wang et al. [86] was mainly focused on producing white light, further studies on CDs are needed to assess their practicality and technical parameters as well as other possible methods for display 


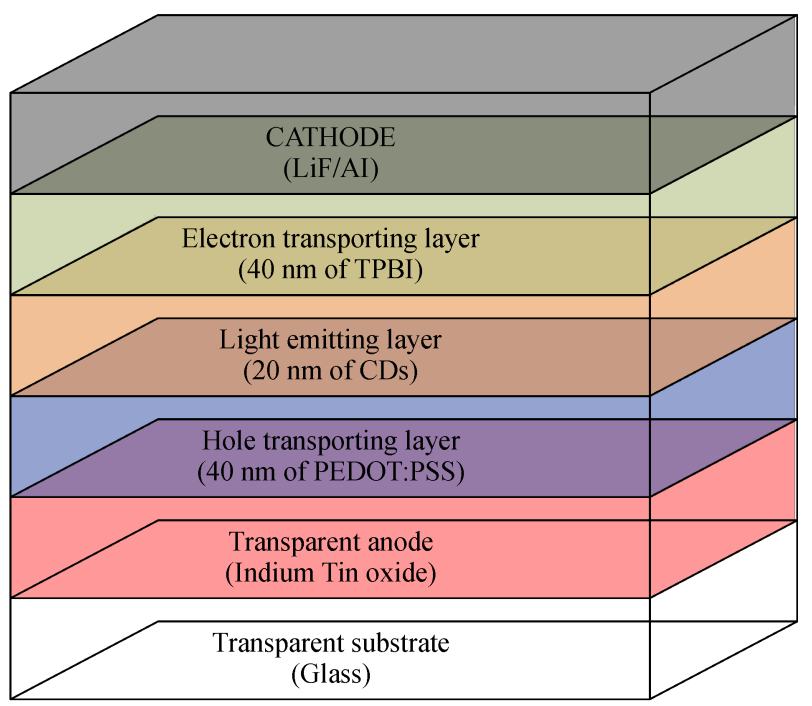

Fig. 11 White light emitting CLED structure [86]
Light emitting diodes (LED)

Carbon-dot light emitting diodes (CLED)

Organic light emitting diodes (OLED) (QLED) and lighting applications. Because one of the most important applications of CDs is for displays and lighting, the response of the human eye to the devices must also be taken into account.

CDs can be used for improving the color performance of other lighting devices or can be used as light emitters for full-color display panels. To achieve these applications, a better understanding of the fundamental and optical properties of CDs must be obtained in order to guide the design and optimization of using them in lighting devices.

\section{Conclusions}

As this review illustrates, the development of lighting technology has largely been dependent on advances in material science and technology. The pros and cons of the various technologies are summarized in Table 4.

LED technology is the future for energy-saving lighting devices, because of its significant reduction in power consumption compared to conventional lights. It is estimated that in Germany alone, LEDs could reduce power consumption by 7.5 billion kilowatt-hours a year. Moreover, LEDs have much longer lifetimes. It is estimated that current high-performance LEDs can last for 20 to 25 years, which would also significantly reduce or eliminate environmental disposal problems. In addition, solid state lighting devices have changed the concept of general lighting not only in terms of energy efficiency but also in opportunities for versatile applications. Both LEDs and OLEDs, being small and thin, can be easily manufactured into any shape for various applications and they can be operated with a minimum use of energy.

Recently developed and emerging nano-materials including QDs and CDs have proven to be useful color filters, fluorescent materials and light emitters for other lighting devices. They also have shown great potential as a new lighting source since they have superior optical performance and can be printed onto any substrate by inexpensive printing processes. This will allow production of highly flexible lighting or display devices for unlimited application areas with minimal cost.
Table 4 Comparison of lighting technologies

\begin{tabular}{llll}
\hline Types & Operating mechanism & Advantages & Disadvantages \\
\hline Incandescent lamps & $\begin{array}{l}\text { Incandescence: light emission by } \\
\text { heating a inner filament }\end{array}$ & $\begin{array}{l}\bullet \text { No external equipment for } \\
\text { operation }\end{array}$ & $\begin{array}{l}\bullet \text { Low efficiency (2\% of their power } \\
\text { input to visible light) }\end{array}$ \\
Fluorescent lamps (FL) & $\begin{array}{l}\text { Electrical discharge: mercury vapor } \\
\text { excited by electrons generating UV } \\
\text { light which is then absorbed by a } \\
\text { phosphor to produce visible light }\end{array}$ & $\begin{array}{l}\bullet \text { lower heat emission than } \\
\text { incandescent lamps }\end{array}$ & $\begin{array}{l}\bullet \text { Safety and environmental issues } \\
\text { including the use of mercury }\end{array}$ \\
\end{tabular}

- 50 times longer lifetime than fluorescent lamps

- Solid state component

- $80 \%$ less power consumption than fluorescent lamps

Electroluminescence: organic emissive electroluminescent layer

Quantum-dot light emitting diodes

Electroluminescence: quantum-dot emissive electroluminescent layer
- Thin and light weight

- Better efficiency than LED as display devices

- Thin and light weight

- Better efficiency as display devices

- Longer lifetime than OLED as

QDs are inorganic materials

- Thin and light weight

- Non-toxic pure carbon based material
- Due to initial cost, more expensive unit price per lumen than conventional lights

- Limited lifetime of the organic materials

- Current manufacturing cost

- Contains heavy metals including cadmium

- There is a restriction or ban on the use of heavy metals in household goods
Electroluminescence: carbon-dot emissive electroluminescent layer 
1 The LED evolution has already begun and future innovations will strongly depend on future discoveries of new materials and processing technologies.

\section{Abreviations}

FL Fluorescent Lamp

CFL Compact Fluorescent Lamp

10 FFL Flat Fluorescent Lamp

CCFL Cold Cathode Fluorescent Lamp

EEFL External Electrode Fluorescent Lamp

LCD Liquid Crystal Display

15 TFT LCD

Thin Film Transistor Liquid Crystal Display

LED Light Emitting Diode

OLED Organic Light Emitting Diode

QD Quantum Dots

20 QLED

$\mathrm{CD}$

Quantum-Dot Light Emitting Diode

Carbon Dots

CLED

\section{References}

1. Kramer T. Seeing the Light. Evonik Magazine, 2010, 2: 12-19

2. Khan N, Abas N. Comparative study of energy saving light sources. Renewable \& Sustainable Energy Reviews, 2011, 15(1): 296-309

3. Park J, Lim S. LCD backlights, light sources, and flat fluorescent lamps. Journal of the Society for Information Display, 2007, 15(12): 1109-1114

4. Lin M, Ho W, Shih F, Chen D, Wu Y. A cold-cathode fluorescent lamp driver circuit with synchronous primary-side dimming control. IEEE Transactions on Industrial Electronics, 1998, 45(2): 249-255

5. Jacob B. Lamps for improving the energy efficiency of domestic lighting. Lighting Research \& Technology, 2009, 41(3): 219-228

6. Arik M, Setlur A. Environmental and economical impact of LED lighting systems and effect of thermal management. International Journal of Energy Research, 2010, 34(13): 1195-1204

7. Mooney J. Fluorescent Lamps. Transactions of the Kansas Academy of Science, 1951, 54(4): 504-505

8. Nakamura H. Recent development of white LEDS and solid state lighting. Light \& Engineering, 2009, 17(4): 13-17

9. Duagal A, Heller C, Shiang J, Liu J, Lewis L. Solution-processed organic light-emitting diodes for lighting. Journal of display technology, 2007, 3(2): 184-192

10. Kim S O, Lee K H, Kim G Y, Seo J H, Kim Y K, Yoon S S. A highly efficient deep blue fluorescent OLED based on diphenylaminofluorenylstyrene-containing emitting materials. Synthetic Metals, 2010, 160(11-12): 1259-1265

11. Hewitt P C. Electric gas lamps and gas electrical resistance phenomena. Transactions of the American Institute of Electrical Engineers, 1902, XIX: 59-65

(New York, N.Y.), 2003, 23(10): 879-886

13. Timothy B U S. Patent, 2001038264, 2001-04-12

14. Koo H, Chang C, Cho N, Lee J. Development and application of less-mercury flat fluorescent lamps for backlights and general lighting. Journal of the Society for Information Display, 2008, 16(7): 759-764

15. Thaler E, Wilson R, Doughty D, Beers W. Measurement of mecury bound in the glass envelope during operation of fluorescent lamps. Journal of the Electrochemical Society, 1995, 142(6): 1968-1970

16. Chang T C, You S J, Yu B S, Chen C M, Chiu Y C. Treating highmercury-containing lamps using full-scale thermal desorption technology. Journal of Hazardous Materials, 2009, 162(2-3): 967972

17. Della P P. US Patent, $3657589,1927-04-18$

18. Elenbaas W. Fluorescent lamps. 2nd. London: Macmillan, 1971

19. Lin D, Yan W. Modeling of cold cathode fluorescent lamps (CCFLs) with realistic electrode profile. IEEE Transactions on Power Electronics, 2010, 25(3): 699-709

20. Alberts I, Barratt D, Ray A. Hollow cathode effect in cold cathode fluorescent lamps: a review. Journal of Display Technology, 2010, 6 (2): 52-59

21. Patent L E E C L. US 2005057143, 2005-11-08

22. Guangsup Cho, Lee J Y, Lee D H, Kim S B, Song H S, Jehuan Koo, Kim B S, Kang J G, Choi E H, Lee U W, Yang S C, Verboncoeur J P. Glow discharge in the external electrode fluorescent lamp. IEEE Transactions on Plasma Science, 2005, 33(4): 1410-1415

23. Cho K, Oh W, Moon G, Park M, Lee S. Study on the equivalent model of an external electrode fluorescent lamp based on equivalent resistance and capacitance variation. Journal of Power Electronics, 2007, 7(1): 38-43

24. Lim D S. US Patent, 2006126332, 2006-06-15

25. Hironori I. Japanese Patent, 2004079270, 2004-03-11

26. Jinno M, Okamoto M, Takeda M, Motomura H. Luminance and efficacy improvement of low-pressure xenon pulsed fluorescent lamps by using an auxiliary external electrode. Journal of Physics. D, Applied Physics, 2007, 40(13): 3889-3895

27. Hu W, Liu Z, Yang M. Luminescence characteristics of mercuryfree flat fluorescent lamp with arc-shape anodes. IEEE Transactions on Consumer Electronics, 2010, 56(4): 2631-2635

28. Jung J C, Lee J K, Seo I W, Oh B J, Whang K W. Electro-optic characteristics and areal selective dimming method for a new highly efficient mercury-free flat fluorescent lamp (MFFL). Journal of Physics. D, Applied Physics, 2009, 42(12): 125205

29. Winsor M, Flynn J. 16.1: Uniform discharge hybrid flat fluorescent lamp (HFFL). SID Symposium Digest of Technical Papers, 2007, 38 (1): 979-982

30. Uhrlandt D, Bussiahn R, Gorchakov S, Lange H, Loffhagen D, Notzold D. Low-pressure mercury-free plasma light sources: experimental and theoretical perspectives. Journal of Physics. D, Applied Physics, 2005, 38(17): 3318-3325

31. Shur M, Zukauskas A. Solid-state lighting: toward superior illumination. Proceedings of the IEEE, 2005, 93(10): 1691-1703

32. Holonyak N, Bevacqua S F. Coherent (visible) light emission from $\mathrm{Ga}\left(\mathrm{As}_{1-x} \mathrm{P}_{x}\right)$ junctions. Applied Physics Letters, 1962, 1(4): $82-83$

33. Nakamura S, Senoh N, Iwasa N, Nagahama S. High-brightness 
ingan blue, green and yellow light-emitting-diodes with quantumwell structures. Japanese Journal of Applied Physics, 1995, 34(Part 2, No. 7A 7A): L797-L799

34. Nakamura S. III-V nitride based light-emitting devices. Solid State Communications, 1997, 102(2-3): 237-248

35. Li H, Zhang C, Li D, Duan Y. Simulation of transform for external quantum efficiency and power efficiency of electroluminescent devices. Journal of Luminescence, 2007 122-123: 626-628

36. Lee S Y, Kwon J W, Kim H S, Choi M S, Byun K S. New design and application of high efficiency LED driving system for RGBLED backlight in LCD pisplay. In: Power Electronics Specialists Conference, 2006, PESC '06. 37th IEEE, 2006

37. Chiu H, Cheng S. LED backlight driving system for large-scale LCD panels. IEEE Transactions on Industrial Electronics, 2007, 54 (5): 2751-2760

38. Cho $\mathrm{H}$, Kwon O. A local dimming algorithm for low power LCD TVs using edge-type LED backlight. IEEE Transactions on Consumer Electronics, 2010, 56(4): 2054-2060

39. Bernanose A. Electroluminescence of organic compounds. British Journal of Applied Physics, 1955, 6(S4): S54-S55

40. Tang C, Vanslyke S. Organic electroluminescent diodes. Applied Physics Letters, 1987, 51(12): 913-915

41. Burroughes J, Bradley D, Brown A, Marks R, Mackay K, Friend R H, Burns P L, Holmes A B. Light-emitting-diodes based on conjugated polymers. Nature, 1990, 347(6293): 539-541

42. Mitschke U, Bauerle P. The electroluminescence of organic materials. Journal of Materials Chemistry, 2000, 10(7): 1471-1507

43. Zhou G, Wong W, Suo S. Recent progress and current challenges in phosphorescent white organic light-emitting diodes (WOLEDs). Journal of Photochemistry and Photobiology, C, Photochemistry Reviews, 2010, 11(4): 133-156

44. Hatwar T K. European Patent, 1492167, 2004-06-14

45. Kisan H T. US Patent, 2007228938, 2007-10-04

46. Lee Y, Ju B, Jeon W, Kwon J, Park O, Yu J, Chin B D. Balancing the white emission of OLED by a design of fluorescent blue and phosphorescent green/red emitting layer structures. Synthetic Metals, 2009, 159(3-4): 325-330

47. Shi J. US Patent, 5935721, 1999-08-10

48. Norimasa Y. European Patent, 2299510, 2011-03-23

49. Tang C W. US Patent, 4769292, 1988-09-06

50. Alsalhi M S, Alam J, Dass L A, Raja M. Recent advances in conjugated polymers for light emitting devices. International Journal of Molecular Sciences, 2011, 12(3): 2036-2054

51. Kim W Y. Recent developments and prospects of organic electroluminescent display technology. Journal of the Korean Physical Society, 1999, 35: S1115-S1119

52. Friend R H, Gymer R W, Holmes A B, Burroughes J H, Marks R N, Taliani C, Bradley D D C, Santos D A D, Brdas J L, Lgdlund M, Salaneck W R. Electroluminescence in conjugated polymers. Nature, 1999, 397(6715): 121-128

53. Alan J. Heeger N S S, Ebinazar B N. Semiconducting and metallic polymers. Oxford: Oxford University Press, 2010

54. Kido J, Kimura M, Nagai K. Multilayer white light-emitting organic electroluminescent device. Science, 1995, 267(5202): 1332-1334

55. Cheng G, Mazzeo M, Rizzo A, Li Y, Duan Y, Gigli G. White lightemitting devices based on the combined emission from red $\mathrm{CdSe} /$
$\mathrm{ZnS}$ quantum dots, green phosphorescent, and blue fluorescent organic molecules. Applied Physics Letters, 2009, 94(24): 243506

56. Chu H Y, Lee J I, Do L M, Zyung T, Jung B J, Shim H K, Jang J. Organic white light emitting devices with an RGB stacked multilayer structure. Molecular Crystals and Liquid Crystals, 2003, 405(1): 119-125

57. Ko C W, Tao Y T. Bright white organic light-emitting diode. Applied Physics Letters, 2001, 79(25): 4234-4236

58. Ping C, Zhang L, Duan Y, Xie W, Zhao Y, Hou J, Liu S, Li B. Efficient white organic light-emitting devices based on blue, orange, red phosphorescent dyes. Journal of Physics. D, Applied Physics, 2009, 42(5): 055115

59. D'Andrade B, Forrest S. White organic light-emitting devices for solid-state lighting. Advanced Materials (Deerfield Beach, Fla.), 2004, 16(18): 1585-1595

60. Reineke S, Lindner F, Schwartz G, Seidler N, Walzer K, Lüssem B, Leo K. White organic light-emitting diodes with fluorescent tube efficiency. Nature, 2009, 459(7244): 234-238

61. Su S J. Highly efficient organic blue-and white-light-emitting devices having a carrier-and exciton-confining structure for reduced efficiency roll-off. Advanced Materials (Deerfield Beach, Fla.), 2008, 20(21): 4189

62. Tsuboi T. Recent advances in white organic light emitting diodes with a single emissive dopant. Journal of Non-Crystalline Solids, 2010, 356(37-40): 1919-1927

63. Murray C, Norris D, Bawendi M. Synthesis and characterization of nearly monodisperse $\mathrm{CDE}(\mathrm{E}=\mathrm{S}$, SE, TE) Semiconductor nanocrystallites. Journal of the American Chemical Society, 1993, 115(19): 8706-8715

64. Colvin V, Schlamp M, Alivisatos A. Light-emitting-diodes made from cadmium selenide nanocrystals and a semiconducting polymer. Nature, 1994, 370(6488): 354-357

65. Steigerwald M, Rice C. Organometallic synthesis of manganese telluride-isolation and characterization of $\left[\left(\mathrm{Et}_{3} \mathrm{P}\right)_{2}(\mathrm{CO})_{3} \mathrm{MNTE}\right]_{2}$. Journal of the American Chemical Society, 1988, 110(13): 42284231

66. Murray C B, Norris D J, Bawendi M G. Synthesis and characterization of nearly monodisperse $\mathrm{CdE}(\mathrm{E}=$ sulfur, selenium, tellurium) semiconductor nanocrystallites. Journal of the American Chemical Society, 1993, 115(19): 8706-8715

67. Katari J, Colvin V, Alivisatos A. X-ray photoelectron-spectroscopy of CDSE nanocrystals with applications to studies of the nanocrystal surface. Journal of Physical Chemistry, 1994, 98(15): 4109-4117

68. Lee J, Sundar V, Heine J, Bawendi M, Jensen K. Full color emission from II-VI semiconductor quantum dot-polymer composites. Advanced Materials (Deerfield Beach, Fla.), 2000, 12(15): 11021105

69. Jang E, Jun S, Jang H, Lim J, Kim B, Kim Y. White-light-emitting diodes with quantum dot color converters for display backlights. Advanced Materials (Deerfield Beach, Fla.), 2010, 22(28): 30763080

70. Li Y, Rizzo A, Mazzeo M, Carbone L, Manna L, Cingolani R, Gigli G. White organic light-emitting devices with $\mathrm{CdSe} / \mathrm{ZnS}$ quantum dots as a red emitter. Journal of Applied Physics, 2005, 97(11): 113501

71. Torriss B, Haché A, Gauvin S. White light-emitting organic device

\section{1}


with electroluminescent quantum dots and organic molecules. Organic Electronics, 2009, 10(8): 1454-1458

72. Kang B H, Seo J S, Jeong S, Lee J, Han C S, Kim D E, Kim K J, Yeom S H, Kwon D H, Kim H R, Kang S W. Highly efficient hybrid ight-emitting device using complex of $\mathrm{CdSe} / \mathrm{ZnS}$ quantum dots embedded in co-polymer as an active layer. Optics Express, 2010, 18(17): 18303-18311

73. Xuan Y, Pan D, Zhao N, Ji X, Ma D. White electroluminescence from a poly( $N$-vinylcarbazole) layer doped with $\mathrm{CdSe} / \mathrm{CdS}$ coreshell quantum dots. Nanotechnology, 2006, 17(19): 4966-4969

74. Coe S, Woo W K, Bawendi M, Bulović V. Electroluminescence from single monolayers of nanocrystals in molecular organic devices. Nature, 2002, 420(6917): 800-803

75. Kim T, Cho K, Lee E, Lee S, Chae J, Kim J, Kim D H, Kwon J Y, Amaratunga G, Lee S Y, Choi B L, Kuk Y, Kim J M, Kim K. Fullcolour quantum dot displays fabricated by transfer printing. Nature Photonics, 2011, 5(3): 176-182

76. Talapin D V, Lee J S, Kovalenko M V, Shevchenko E V. Prospects of colloidal nanocrystals for electronic and optoelectronic applications. Chemical Reviews, 2010, 110(1): 389-458

77. Zorn M, Bae W K, Kwak J, Lee H, Lee C, Zentel R, Char K. Quantum dot-block copolymer hybrids with improved properties and their application to quantum dot light-emitting devices. ACS Nano, 2009, 3(5): 1063-1068

25 78. Gopal A, Hoshino K, Kim S, Zhang X, Hoshino K, Kim S, Zhang X. Multi-color colloidal quantum dot based light emitting diodes micropatterned on silicon hole transporting layers. Nanotechnology, 2009, 20(23): 235201

79. Caruge J, Halpert J, Wood V, Bulovic V, Bawendi M. Colloidal quantum-dot light-emitting diodes with metal-oxide charge transport layers. Nature Photonics, 2008, 2(4): 247-250

80. Kang S, Huh H H, Son K C, Lee C S, Kim K H, Huh C, Kim E T. Light-emitting diode applications of colloidal CdSe/ZnS quantum dots embedded in $\mathrm{TiO}_{2}$-delta thin film. Physica Status Solidi. B, Basic Research, 2009, 246(4): 889-892

81. Sun Y P, Zhou B, Lin Y, Wang W, Fernando K A, Pathak P, Meziani M J, Harruff B A, Wang X, Wang H, Luo P G, Yang H, Kose M E, Chen B, Veca L M, Xie S Y. Quantum-sized carbon dots for bright and colorful photoluminescence. Journal of the American Chemical Society, 2006, 128(24): 7756-7757

82. Li Q, Ohulchanskyy T, Liu R, Koynov K, Wu D, Best A, Kumar R, Bonoiu A, Prasad P N. Photoluminescent carbon dots as biocompatible nanoprobes for targeting cancer cells in vitro. Journal of Physical Chemistry C, 2010, 114(28): 12062-12068

83. Yang S T, Wang X, Wang H, Lu F, Luo P G, Cao L, Meziani M J, Liu J H, Liu Y, Chen M, Huang Y, Sun Y P. Carbon dots as nontoxic and high-performance fluorescence imaging agents. Journal of Physical Chemistry C, 2009, 113(42): 18110-18114

84. Yang S T, Cao L, Luo P G, Lu F, Wang X, Wang H, Meziani M J, Liu Y, Qi G, Sun Y P. Carbon dots for optical imaging in vivo. Journal of the American Chemical Society, 2009, 131(32): 1130811309

85. Wang F, Kreiter M, He B, Pang S, Liu C Y. Synthesis of direct white-light emitting carbogenic quantum dots. Chemical Communications, 2010, 46(19): 3309-3311

86. Wang F, Chen Y H, Liu C Y, Ma D G. White light-emitting devices based on carbon dots' electroluminescence. Chemical Communications, 2011, 47(12): 3502-3504 